\title{
Automated Periodicals System at a Community College Library
}

\begin{abstract}
Vivian HARP: Staff Analyst, Illinois Bell Telephone Company, Chicago, and Gertrude HEARD: Serials Technician, Moraine Valley Community College Library, Palos Hills, Illinois. At the time of writing, Ms. Harp was Assistant Librarian at the Moraine Valley Community College Library.
\end{abstract}

Automated systems need not be extensive to save time and improve efficiency. Moraine Valley's off-line operation, based on a file of 715 periodical titles, generates renewal orders, sends claims, and records subscription histories.

\section{BACKGROUND}

Moraine Valley Community College (MVCC) is a two-year institution serving southwest Cook County, Illinois. It opened in September 1968 and now has an enrollment of 3,468 students. The library maintains 715 paid and free periodical subscriptions.

Because of the small staff size, periodicals had originally been handled by the cataloger. Two subscription agencies were tried and found unsatisfactory. Problems with overlapping subscriptions and lapsed subscriptions which were never picked up became quite severe, and time spent tracking down problems approached that needed to handle orders and renewals independently. Periodicals were transferred to the public service librarian when the staff was expanded. As untangling of agency problems proved more and more time-consuming, a serials technician was assigned to maintain subscriptions, straighten out old problems, check in periodicals, and handle claims.

For each subscription, bibliographic and order information and MVCC holdings were entered on a three-by-five-inch history card; on the verso were records for each renewal of purchase order number, subscription length, cost, and subscription dates. Magazines were and are checked in on Kardex files; the Kardex card also holds the latest publisher's mailing label. A checklist is used to ensure that each new title has a Kardex card and storage box prepared and a listing in the public holdings record, plus any special instructions for routing. Form letters are used for original enquiries to the publisher regarding availability and cost.

When a subscription was renewed, data from the "current" section of 
the history cards had to be transferred to the back and updated information entered on the front. A worksheet was made up to give all the necessary renewal information to the typist and the actual purchase order typed from that worksheet. Once the purchase order was completed its number was marked on the worksheet and the history card. Worksheets were kept on file to serve as easily accessible copies of the purchase orders for use in correspondence since the library copy of the purchase order was tied up in the accounting process.

Since many publishers do not provide renewal notification-and in our case these renewals amounted to over 40 percent of our orders-various methods to provide ourselves with notification of approaching expirations were attempted, including the use of colored plastic jackets in the history card file and division of the file by date. Failure in this area was the chief weakness of the manual system. The cards were bulky and required much handling. Creating a holdings list destroyed any semblance of the colorcoded order. If a card were removed for use in correspondence, it could be misplaced or misfiled and therefore not be considered for renewal at the proper time. Duplication of paperwork and repeated erasures and transfers of information on the cards were other drawbacks of this operation.

\section{INTRODUCTION TO AUTOMATED SYSTEM}

It was hoped that an automated system would indicate approaching expirations and simplify the actual renewal procedure. The following specific objectives were set up:

1. To provide advance notice of subscriptions due for renewal even if a renewal notice were not received.

2. To produce a purchase order, or a replica providing on a single sheet all data needed for renewal.

3. To produce a list of periodical holdings that included the history of all renewals.

4. To claim missing issues of paid and free subscriptions.

5. To produce fiscal and subject area cost reports that would facilitate budget evaluation.

Two special problems had to be given consideration: (1) the college has a complicated check approval system requiring initiation of purchase orders two months before the check is needed; and (2) the automated system needed the capability to handle standing orders, government documents (depository and agency items), free materials, and titles held only on microfilm as well as ordinary renewals. These special items make up almost 30 percent of the total subscriptions, and to maintain a parallel manual system for them would be unsatisfactory.

\section{METHOD AND MATERIALS}

Selecting data elements for inclusion was based as much as possible on 
the types of output reports desired. A simple holdings list as an end in itself was felt to be wasted effort, but as a by-product of the master file we wanted to generate public holdings lists twice a year.

Necessary data were readily available from the three-by-five-inch cards, with one addition-a unique number was assigned to each title. The data necessary would require more than one input card to produce the type of reports we wanted; therefore, as data elements were being considered, card codes and item numbers were also assigned to identify information for programming purposes. Space was allocated to each field, using information recorded on the history cards, and the coding of certain fixed and variable fields was decided upon. The card formats are outlined in Figure 1. Figures 2 and $2 \mathrm{~A}$ list the codes and their meanings.

All Cards-Column 1-5 Unique Number

6 Card Code

\section{Card 1}

$C C$

7 Type of material (coded)

$8 \mathrm{X}$ (cancel) or $\mathrm{H}$ (hold) (coded)

9-66 Title

67 Type of subscription (coded)

68 How to pay (coded)

69 Years subscription runs

70-71 Account charged (coded)

72-76 Cost

77-80 Renewal date

Card 2

CC

7-15 Invoice number

16-24 Periodical holdings

25-33 Microfilm holdings

34-39 Purchase order number

40-48 Subscription length data

49-51 Frequency (coded)

52-74 Indexing (coded)

75-79 Blank

80 Method of payment

Card 3

CC

7-80 Publisher's name
Card 4

CC

7-40 Publisher's street address

41-43 Subject code (coded)

44-49 Purchase order date

$50 \quad$ Blank

51-75 Publisher's city, state

76-80 Publisher zip code

Cards 5, 6, 7, 8 \& 9

CC

7-80 Publisher's mailing label data

Card A

CC

7-80 Claim information

Card B-History

CC

7-12 Purchase order number

13-17 Date history transferred

18-26 Dates subscription ran

27-31 Cost

32 No. years subscription ran

33-80 Invoice number

Card $C$

CC

7-80 Comments

Fig. 1. Field Descriptions 
Card 1

CC-7-Type of Material

$\mathrm{P}-$ Periodicals

I-Index

V-Vertical File

M-Microfilm

$\mathrm{N}$-Newspapers

A-Membership (Assoc.)

L-Librarians File

CC-67-Type of Subscription

$\mathrm{N}-\mathrm{New}$

R-Renewal

CC-68-How to Pay

$\mathrm{R}$-Check Request

I-Imprest Fund

T-Invoice in Triplicate

CC-70-71-Acct. to Be Charged

L-Library

B-Biology

$\mathrm{H}-$ Humanities

P-Physics

SS-Social Science

HS-Health Science

T-Technology

BU-Business

E-Economics

Card 2

CC-49-51-Frequency

S-Sunday only

D-Daily

D\&S-Daily \& Sunday

W-Weekly

Q-Quarterly

A-Annually

BIW-Every 2 weeks
BIM-Every 2 months

SMO-Semimonthly

SAN-Semiannually

IRR-Irregular

$3 / y-T h r e e$ times a year

$5 / y-F i v e$ times a year

$7 / \mathrm{y}-$ Seven times a year

$9 / \mathrm{y}-$ Nine times a year

$10 / y-$ Ten times a year

$11 / \mathrm{y}-$ Eleven times a year

CC-52-73-Indexing

01-Index Medicus

02-Applied Science and Technology

03-Business Periodicals Index

04-Education Index

05-International Nursing Index

06-Library Literature

07-MLA Bibliography

08-Nursing Literature Index

09-Public Affairs Information Science

10-Readers Guide to Periodical Literature

11-Social Science and Humanities Index

12-New York Times Index

13-Art Index

00-No Index

CC-80-Method of Payment

A-Payment Enclosed

B-Payment and Notice Enclosed

C-Please Invoice in Triplicate

D-Payment and Invoice Copy Enclosed

Fig. 2. Coding Symbols and Meanings

Input transmittal forms were designed with the aid of the Information Systems staff to record information for use in keypunching. Forms shown in Figures 3, 4, and 5 illustrate the transmittal of information for keypunching. While customized data transmittal forms are available commercially, it was found just as satisfactory and much more economical to design our own forms and have them reproduced by college facilities.

Since our main consideration in choosing information for inclusion was 


001 Accounting
002 Aeronautics
003 African Studies
004 Afro-American
005 Agriculture
006 Anthropology and Archaeology
007 Architecture
008 Art
009 Astronomy
010 Automation
011 Banking and Finance
012 Bibliography
013 Biological Sciences
014 Boats and Boating
015 Bool Reviews
016 Business and Industry
017 Chemistry
018 Cities and Towns
019 Conservation
020 Crafts and Hobbies
021 Criminology and Law
022 Dnforcement
023 Dissident Magazines
024 Economics
025 Education
026 Engineering
027 English
028 Entertainment
029 Fire Fighting
030 Fishing and Hunting
031 Folklore
032 Games and Sports
033 General
034 Geography
035 Geriatrics
036 German Language
02

037 Government

038 Health Science

039 History

040 Home

041 Indexes and Abstracts

042 Journalism

043 Labor and Industrial Relations

044 Library Periodicals

045 Linguistics and Philology

046 Literary and Political Reviews

047 Literature

048 Mathematics

049 Men's Magazines

050 Military

051 Motion Pictures

052 Music

053 Newspapers

054 Ornithology

055 Philosophy

056 Photography

057 Physics

058 Political Science

059 Psychology

060 Radio, TV, and Electronics

061 Religion and Theology

062 Romance Languages

063 Science-General

064 Slavic Languages

065 Sociology

066 Theatre

067 Travel

068 Traffic and Transportation

069 Vocations and Vocational Guidance

070 Women's Magazines

071 Memberships

072 Social Work

Fig. 2A. Codes Used for Periodical Subject List

to overcome our renewal problems, we had to determine what information was needed for this purpose. If purchase orders were to be generated, a field to be used as a key would be required. The program would check the contents of this key to determine whether or not the subscription was due for renewal. Since the logical key seemed to be the expiration date, it was allowed a separate field (Figure 3, Item 009), even though this partially 
MVC
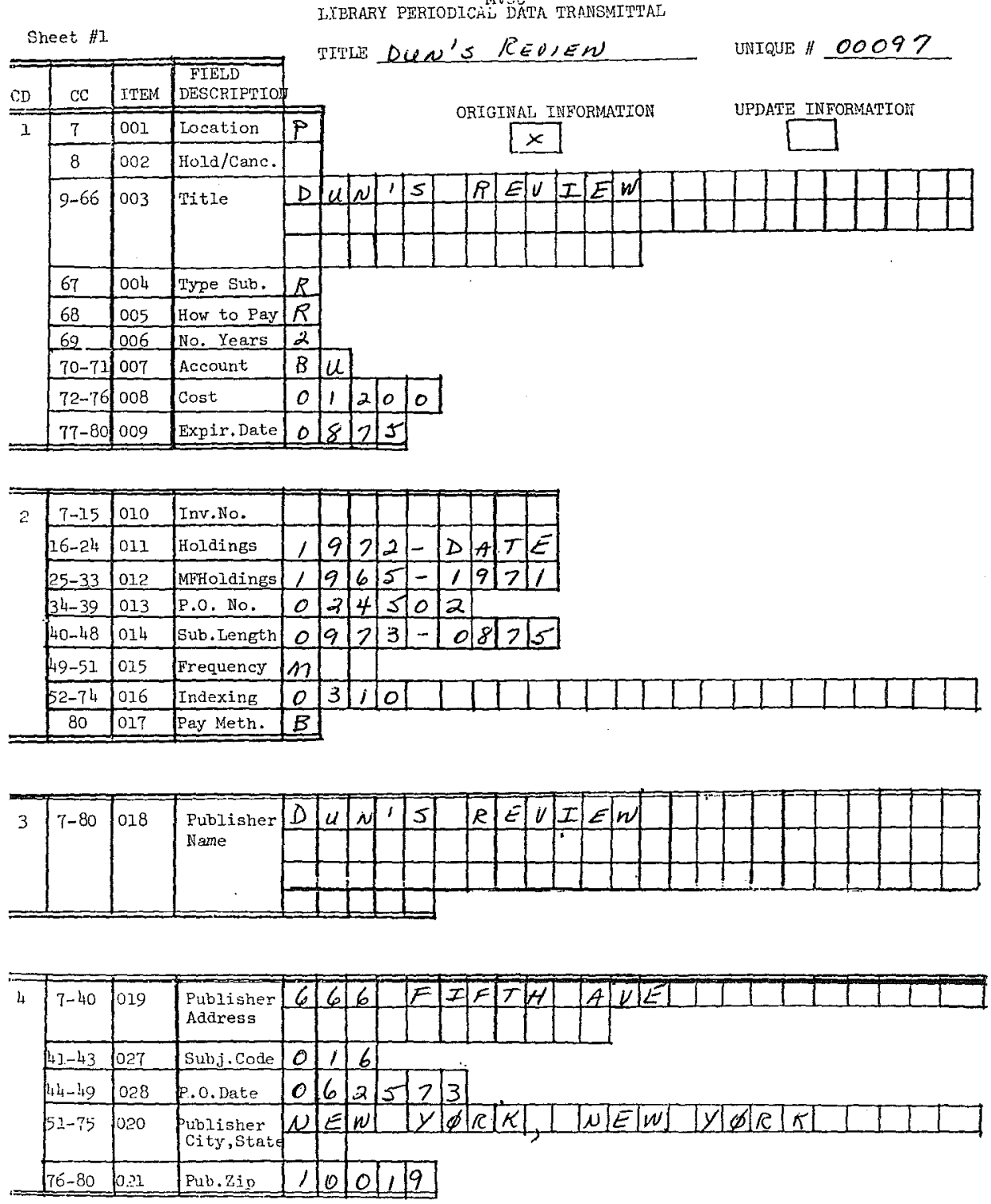

Fig. 3. Library Periodical Data Transmittal Form

duplicated the subscription length field. (The subscription length field itself was to be kept intact for transfer to the history record.) A one-position field (Figure 3, Item 002) could be programmed to suppress printing of a purchase order, as in the case of a canceled subscription, or to keep the order in "hold" if a budget problem arose near the end of the fiscal year. Hold status would cause the order to be printed with the tag "Pay when authorized" to call attention to this status. Other fields shown in Fig- 
MVCC

LIERARY PERIODICAL DATA TRAISMITTAL

Sheet th2 TITLE DUN'S REVIEW UNIQUE \# 00097

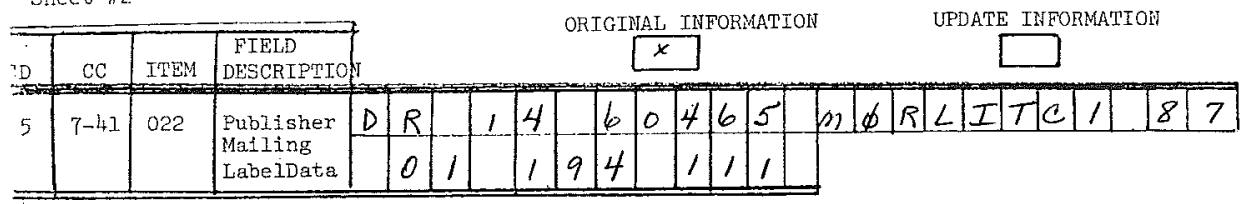

\begin{tabular}{|c|c|c|c|c|c|c|c|c|c|c|c|c|c|c|c|c|c|c|}
\hline 6 & $7-41$ & 023 & $\begin{array}{l}\text { Publisher } \\
\text { Mailing }\end{array}$ & (2) & $\phi 1$ & $R$ & $A I$ & $\sim$ & $E$ & & $v$ & A & $\angle \angle$ & $E Y$ & C) & $\phi[m$ & $n+y$ & $\mid c$ \\
\hline & & & LabelData & $\not$ & $\angle$ & $L$ & 0 & 8 & 7 & 3 & 8 & 2 & 0 & $d$ & & & & \\
\hline
\end{tabular}
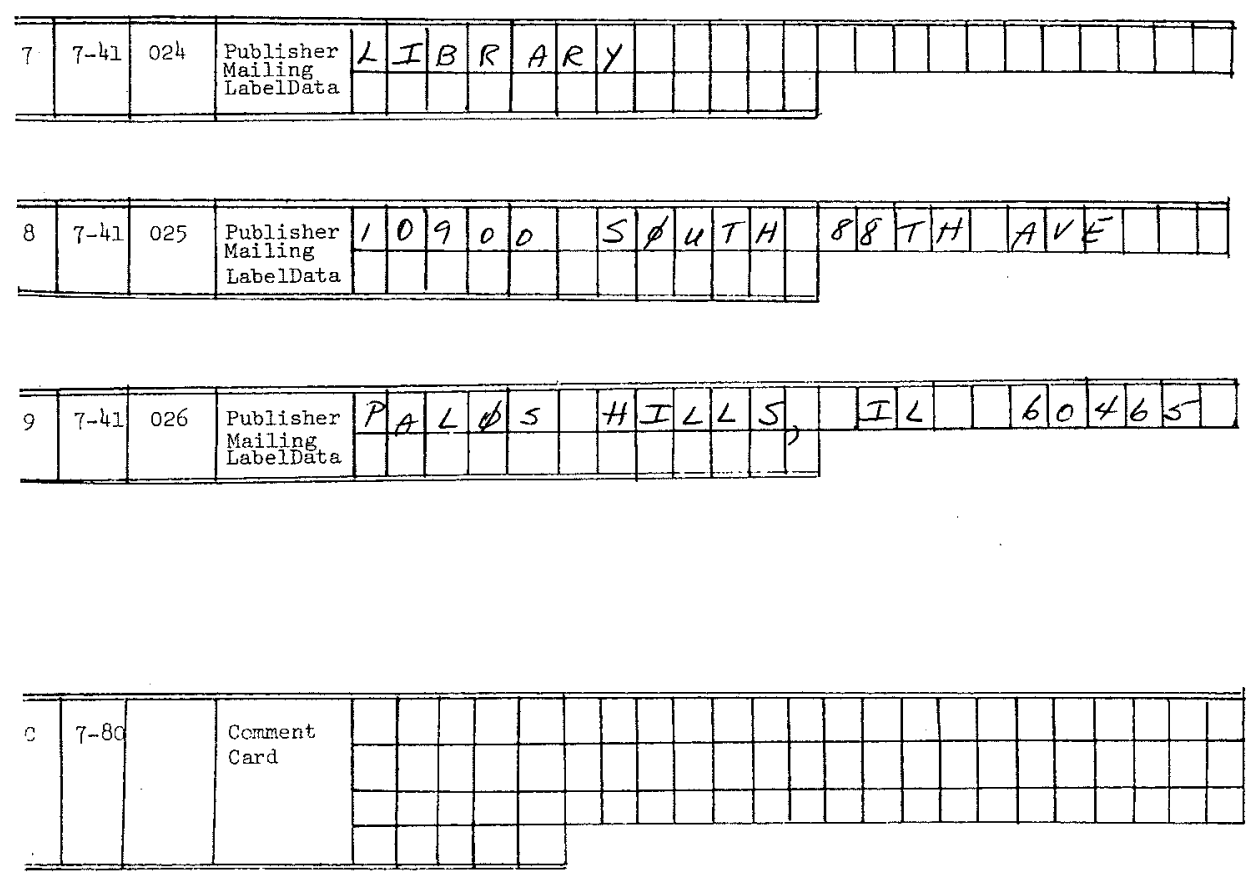

Fig. 4. Library Periodical Data Transmittal Form: Publisher's Mailing Label

ure 3 necessary for the renewal process are: title, type of subscription, how to pay, number of years subscription to run, account to be charged, cost, publisher's name, address, city, state, and zip code. Necessary information shown in Figure 4 includes the publisher's mailing label data. These data permit an exact copy of the publisher's mailing label and are as vital for renewing and claiming as they are necessary for correspondence.

Creation of a holdings list which would include current holdings plus holdings which were on microfilm required the addition of fields for holdings, microform holdings, frequency, and use again of title. All these items are shown on Figure 3.

Handling our own renewals made it very desirable to maintain a com- 
MVCC LTBRARY PERTODICAE DATA TRAMSMTTTAI

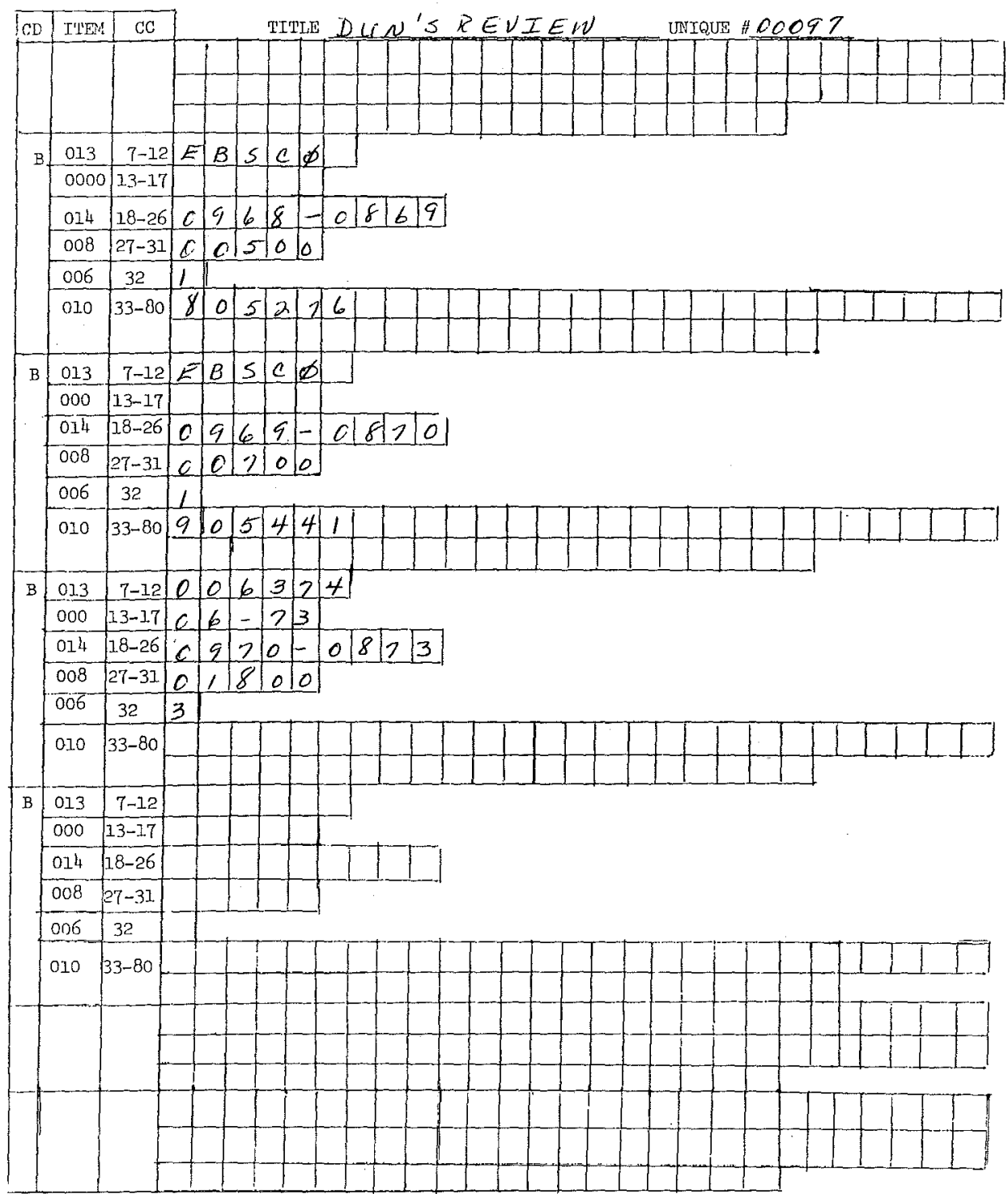

Fig. 5. Historical Record Form

plete file on the history of each subscription. Data necessary to maintain this file were the subscription length and cost fields (described above) and the addition of fields for the purchase order number (Figure 3, Item 013) plus the invoice number (Figure 3, Item 010). The computer program was written so these data could be automatically transferred to the history record card at renewal time. 
SUPERINTENCENT OF DOCUMENTS GOVERNMENT PR INTING DFFICE

WASHINGTON, DC

20402

$02 / 07 / 73$

RE= DUR PUBLIC LANDS

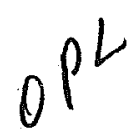

ATTENTION SUBSCRIPTION CLAIMS DEPARTMENT

ACCORDING TO OUR RECORDS, WE HAVE NOT RECEIVED THE FOLLOWING ISSUE(S). IF DUR SUBSCRIPTION IS IN ORDER, KINDLY SEND OUR MISSING ISSUES.

VOLUME 22, IS SUE NO.3a-SUMMER 1972

THANK YOU

MORAINE VALLEY COMMUNITY COLLEGE LIBRARY

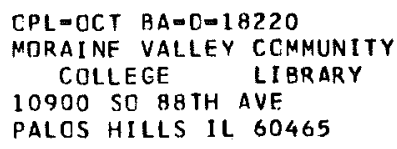

Fig. 6. Claims Letter

Claims data are transmitted as needed by providing the unique number of the title and the information concerning the missing issue(s). Claims letters (Figure 6) are then mailed in window envelopes, so no typing is required.

When working with periodicals or serials one becomes accustomed to sudden or unusual changes that occur with or without notice. A few examples could be changes in title, frequency, or general publishing patterns. We wanted to provide our system with the ability to notify us that an investigative procedure had been completed and thus avoid many of the "why's" that recur. Accordingly, we included a comment card (Figure 4, Card C) which can be updated as circumstances require.

From the transmittal forms for the initial batch of titles, cards were keypunched and built into a magnetic tape file. The serials technician now submits updates or additions (e.g., for new titles) within the schedule provided by Information Systems and the tape is updated each month.

The main printed report is run monthly (Figure 7). This master list includes all bibliographic, holding, and renewal information. Titles due for renewal in three months are flagged with asterisks. The technician 
MOR A I NE VALLEY COMHUNITY COLLEGE

$12 / 21 / 73$

PERIODICAL LIST

00097 P DUN'S REVIEW $1972-D A T E$ 1965-1971 $024502 \quad 0973-0875 \quad M \quad 0310$
OUN'S REVIEW

OUN'S REVIEW

DR $14 \quad 60465$ MORLITC1 $87 \quad 01 \quad 194 \quad 111$

MORATNE VALLEY COMNTY COLL 08738200

LIBRARY

10900 SOUTH BBTH AVE

PALOS HILLS, IL 60465

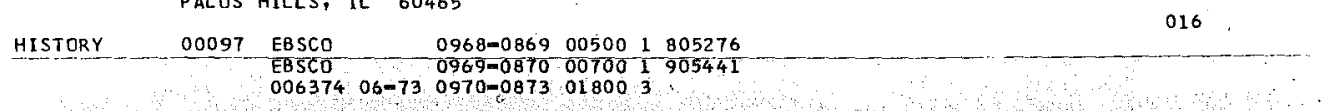

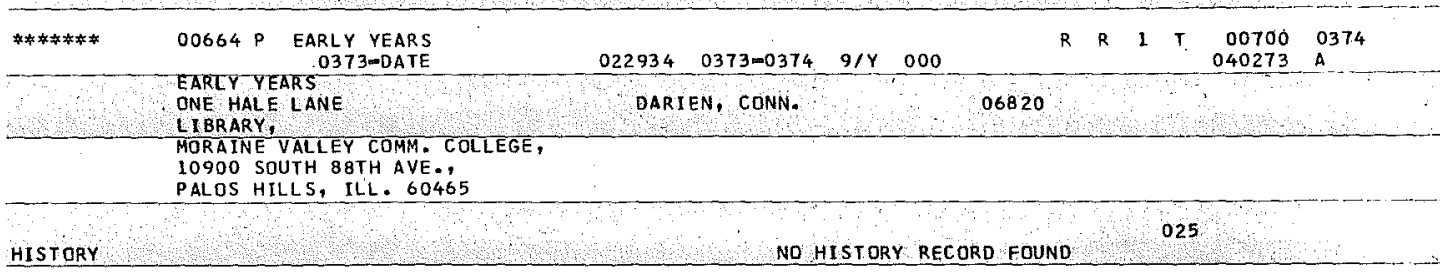

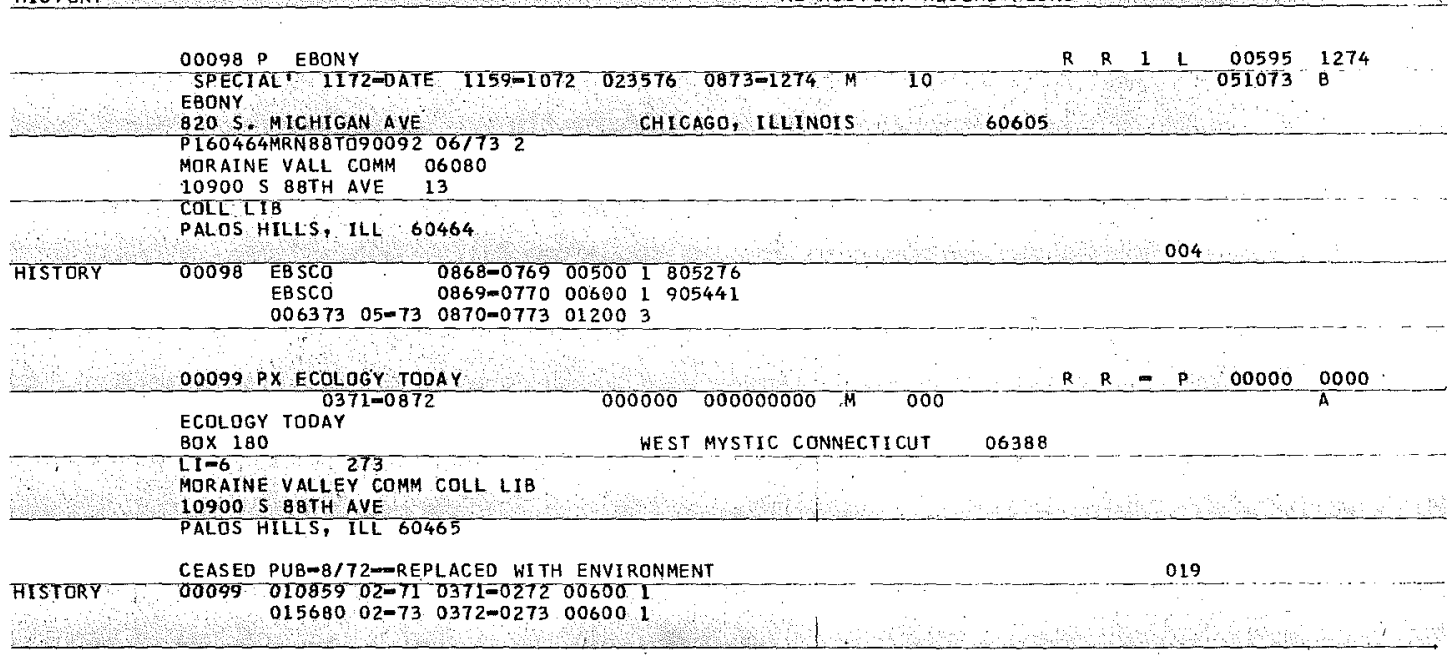

Fig. 7. Master Periodical Printout

determines the current subscription price and number of years to renew each flagged title and updates these fields. At the next monthly run, facsimile purchase orders (containing all revised data except the purchase order number) are printed (Figure 8). The technician types up numbered purchase orders from these and forwards them to the business office in time for payment. We intended our system to utilize purchase order forms to be run directly on the computer. Therefore, our present method of typing from facsimiles does seem wasted effort, but is looked on as a stopgap measure for the present and the inconvenience is tolerated while waiting for the more desirable method. If the computer forms are adopted, we may have increased conflict in price updates because there will be less opportunity for last minute corrections. However, we do plan to avoid as 


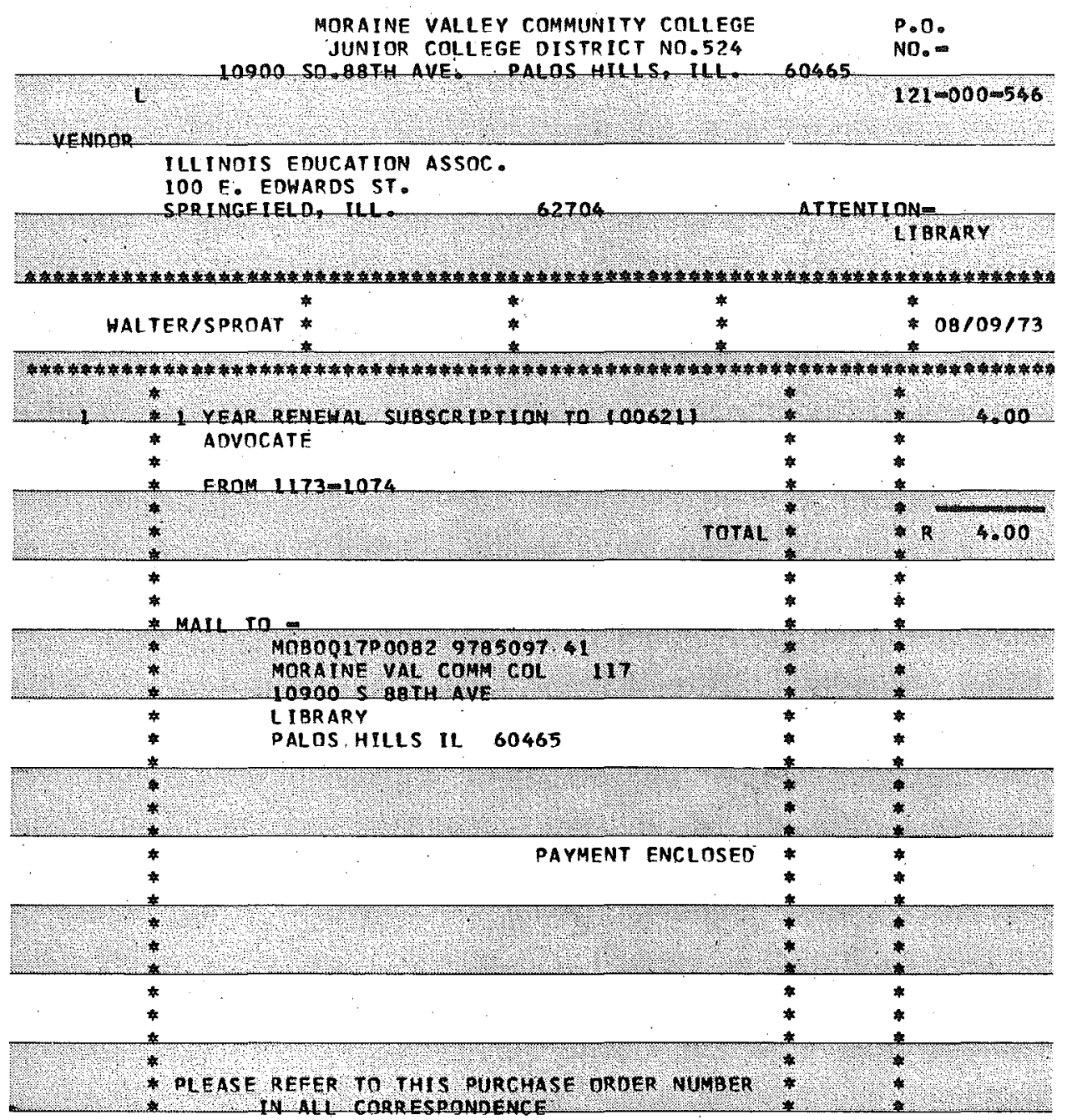

Fig. 8. Facsimile Purchase Order

much conflict as possible by plans to run actual purchase orders closer to the actual expiration date.

The renewal procedure followed involves these steps:

1. Check purchase order facsimiles for accuracy and match with renewal notices received.

2. Check Kardex for material arrival regularity.

3. Type and forward purchase orders to business office.

4. Update forms and send to Information Systems.

5. Scan master list for flagged items and record their unique numbers and titles on update sheets. 
6. Update flagged items with renewal notices as follows:
a. Price.
b. Number of years for renewal.
c. New subscription dates.
d. Method of payment.
e. Any changed information concerning publisher and mailing label.

7. Update flagged items without renewal notices in the same manner, using the latest issue received.

8. As additional renewal notices for flagged items come in, make necessary updates.

9. Send all updates to Information Systems at least three days before the master list and facsimiles are due to be run.

Price changes do occur between the time the item is flagged and the check is mailed. With most, though, notification is received from the publisher before the purchase order is actually typed, and corrections are made at that time.

Since the renewal process is linked to the expiration field, updating that field also causes transfer of data for the year just expired into the history record, as explained earlier. Free materials, government depository items, and standing orders for which invoicing is known to be automatic are handled by filling the expiration date field with zeros. If a purchase order history record is needed, as with standing orders, these fields are updated at the time the invoice arrives.

Our master list does not contain headings to explain field descriptions. We place our master list in a binder; a legend describing placement of field descriptions is attached to the inside of the front of the binder cover and is readily available for reference. We felt headings on each record would be clumsy, confusing, and would waste valuable printing space. Codes and their explanations are attached to the inside of the back of the binder cover.

To date, two revisions have been installed into the system: (1) In 1972 we decided to classify our holdings by subject. Space was "found" for three digits, and we then proceeded to code our subjects (Figure 3, Item 027). Our subject codes and their meanings are explained in Figure 2A. (2) Correspondence was assisted by having all necessary information in one location. The cost, purchase order number, and problem explanation were available by merely flipping the printout pages to the title in question on the master list. However, the date the purchase order was typed had to be looked up in order to effect an intelligent solution. Six spaces were again "found" to provide this purchase order date (Figure 3, Item 028).

Actual computer programming was performed by Information Systems staff in BAL, and programs are run on the college IBM 370-135 computer. 


\section{RESULTS}

It has not been possible to figure actual monetary costs for the library portion and maintenance of this system, nor to compare these costs with the manual system. Libraries have traditionally been weak in figuring operation costs, and we confess to not having been very innovative in this area. We do not have specific itemized costs for our manual routines, so actual comparisons are not possible. A few figures concerning library time can be given. From October through December of 1971, when the initial phase was set up, the serials technician and public services librarian each contributed about 20 percent of their time, and a student aide worked 10 to 15 hours per week on the clerical part of the data transmittal. Since that time the system has been operational for over two years, and some time approximations concerning updating, adding to the file, etc., are now available. With development behind us, time contributed by the serials technician, who is now solely responsible for the maintenance of the system, has dropped from 20 percent to between 5 and 15 percent. Exact costs are difficult to extract, since this varies during the year according to the number of renewals due in particularly heavy expiration months as compared with those due in light expiration months.

The library as part of the college is not charged for use of computer facilities. Figures for machine time and keypunching are available and are as follows:

\section{Program}

Periodical additions per 100 titles

Periodical updates per 100 titles

Purchase order printing

Claim disbursements

Miscellaneous reports
Machine
Time (hr.)

.1

.1

.5

.1

3.0
Keypunch

Time (hr.)

8.0

2.0

Information Systems has given their monetary cost in developing this system as $\$ 5,970$ for programming time. They also figure program maintenance at $\$ 215$ per year and the cost to run programs per year at $\$ 256$.

We can list important benefits we have derived. Renewal problems have been eliminated. The few duplicate problems can be handled now as soon as they occur. Our system handles all types of live subscriptions and the "dead file" as well. There is no more fussing with cards since we have a one-stop, clear record of holdings and histories, including the entire invoice and payment record for each subscription. At renewal time all the information for purchase orders is listed on a single-sheet facsimile. Claim letters are done for us and we can call for various listings as they are needed. Reports we receive are: master listing once a month, purchase order facsimiles once a month, claim letters as needed, fiscal year total cost re- 
ports, fiscal year area cost reports, subject lists as needed, holdings lists as needed, unique number lists as needed.

\section{CONCLUSIONS}

Many librarians having access to sophisticated computer facilities content themselves with producing a more or less elaborate holdings list. Subscription placements and renewals are handled manually, often through a commercial agency. Common agency problems such as overlapping and lapsed subscriptions are simply tolerated. We feel from our experience that if enough effort is expended to create a successfully operating holdings list, a small library does not require much further effort to add renewal, history record, and claiming functions. This eliminates agency problems, provides the ability to manipulate files for producing various reports, and in our opinion, results in more efficient and convenient record-keeping.

The size of our operation falls at the lower end of a range of libraries having holdings large enough to require at least one individual's time. Translated into figures, we feel that any automated system would be wasted on holdings of under 150 periodicals. The crucial factor in relation to size is not really any magic number of holdings but the ratio of available staff time to the size of the holdings. This factor must be evaluated by libraries considering any type of automated system. We feel much of the success of our system has been dependent upon our initial planning, our staff availability, and our conviction that a change was necessary to eliminate the problems we were encountering with our manual system. Also the availability of the computer facilities, the encouragement provided by our superiors, and adequate library staff and Information Systems staff all contributed to an efficient changeover.

\section{ACKNOWLEDGMENTS}

Gratitude is due Moraine Valley Community College for its permission and support of this innovation. Particular gratitude is due Anabel Sproat, head librarian, for her permission, support, and constant encouragement. The excellent work and friendly attitude of Linda Nemeth and the entire Information Systems staff who made this project a reality have been deeply appreciated. Also, the capable assistance of student aide Barbara Hart (Goeske) in the recording process proved to be a very valuable asset. 